\title{
PENGARUH PENGEMBANGAN KURIKULUM PENDIDIKAN AGAMA \\ ISLAM TERHADAP PRESTASI BELAJAR MATA PELAJARAN \\ PENDIDIKAN AGAMA ISLAM SISWA \\ SMA TUNAS LUHUR PAITON PROBOLINGGO
}

\author{
M. Inzah*
}

\begin{abstract}
The Effect of Islamic Education Curriculum Development on the Achievement of Learning Subject of Islamic Religious Education High School Student Tunas Luhur Paiton Probolinggo, This research is a quantitative research with descriptive analysis approach and simple regression analysis to 20 randomly selected sample people. Curriculum development data obtained from the accumulation of some test scores held by TPQ SMATL.Pengembangankurikulum Islamic education and learning achievement subjects PAI SMATL students have a strong or significant relationship with the value of $r$ calculated results (0.681) larger than rtabel (0.444) at a significance level of 5\%. Result of regression analysis obtained conclusion that curriculum development give positive influence to learning achievement of PAI, marked by slope value (slope) positive regression line equal to 0,690. The regression equation obtained $(Y=35,558+0,690 X)$ can also explain the diversity of student achievement score significantly based on the result of further analysis with F-value test $(15,548)$ bigger than Ftabel $(4,41)$ at significance level $5 \%$ and with the test of coefficient of determination ( $r 2)$ value of 0.463. Overall, thus, the proposed hypothesis is accepted, ie that there is a significant (positive) influence of the development of Islamic education curriculum on the achievement of learning subjects PAI high school students Tunas Luhur Paiton Probolinggo.
\end{abstract}

Keywords: Curriculum, Education, Religion, SMA Tunas Luhur

\footnotetext{
* Dosen tetap Fakultas Tarbiyah INZAH Genggong Kraksaan
} 


\section{A. Pendahuluan}

Pendidikan agama saat ini menuaibanyak kritik yang tajam karena tidak mampu menanggulangi berbagai problempentingkehidupan masyarakat,seperti menghargai kepercayaan keagamaandan keragaman kultur yang beranekaragam. Hal ini indikasinya akanmelahirkan konflik SARA(Suku, Agama, Ras dan AntarGolongan). ${ }^{1}$ Sejumlah persoalan tersebut sangat memiliki keterkaitan dengan penyelengaraan pendidikan agama di lapangan sehingga peran dan keefektifannya di pertanyakan. ${ }^{2}$

Uraian diatas menjadi indikasi bahwa pendidikan agama di sekolah menghadapi problem yang perlu segera diatasi agar sesuai dengan tujuan yang di harapkan. Salah satunya adalah perlu adanya pengembangan kurikulum khususnya kurikulum PAI dalam tingkat satuan pendidikan.

Pengembangan kurikulum adalah hal yang harus dilakukan oleh setiap sekolah dan lembaga pendidikan, hal ini bertujuan agar tujuan pendidikan dapat tercapai secara maksimal. Hal tersebut sesuai dengan pernyataan mantan Direktur Jenderal Pendidikan Dasar dan Menengah (Dikdasmen) Departemen Pendidikan Nasional (Depdiknas), Indra Jati Sidi, sebagai berikut:

"Sekolah tidak dilarang untuk mengembangkan kurikulum sendiri.

Dalam kaitan ini, sekolah seharusnya lebih kreatif mengembangkan kurikulum yang bermanfaat bagi peserta didik, tanpa harus menunggu petunjuk dari pemerintan. Hanya saja pengembangan itu harus tetap berdasarkan pada desaion kurikulum nasional". ${ }^{3}$

Pengembangan kurikulum KTSP dalam konsteks ini adalah kurikulum PAI, disusun sebagai wujud pelayanan kepada masyarakat yang mempunyai latar belakang budaya dan adat istiadat yang berbeda antar ssatu daerah dengan daerah yang lain. Oleh karena itu pengembangan kurikulum PAI harus mampu melayani kebutuhan masyarakat, dengan memfokuskan pengembangan pada kompetensi tertentu yang berupa pengetahuan agama, keterampilan beragama, sikap yang utuh dan terpadu antara ilmu dan amal, serta kemampuan peserta didik mendemonstrasikannya sebagai wujud hasil belajar dengan pendekatan Informal cultural religious agar dapat diterima masyarakat. ${ }^{4}$

Pengembangan kurikulum adalah istilah yang komprehensif, di dalamnya mencakup perencanaan, penerapan dan evaluasi, bahkan tidak hanya melibatkan orang yang terkait langsung dengan dunia pendidikan saja, namun di dalamnya

\footnotetext{
${ }^{1}$ Syamsul Ma'arif, Pendidikan Pluralisme di Indonesia (Yogyakarta: Logung Pustaka, 2005), 5

${ }^{2}$ Ahmad Najib Burhani, Menggugat Peran Agama Membongkar doktrin yang membatu (Jakarta: Kompas, 2001), 205

${ }^{3}$ http/www.kemendiknas com.

4 Rahmat Raharjo, Inovasi Kurikulum Pendidikan Agama Islam pengembangan kurikulum dan pembelajaran (Depok Sleman: Magnum Pers, 2010), 41.
} 
juga melibatkan banyak element instansi terkait, seperti: politikus, pengusaha, orang tua peserta didik, serta unsur-unsur masyarakat lainnya yang merasa berkepentingan dengan pendidikan.

Permusan masalah dalam penelitian ini yaitu: Bagaimana pelaksanaan kurikulum pendidikan agama Islam SMA Tunas Luhur Paiton Probolinggo?Bagaimana pengembangan kurikulum pendidikan agama Islam SMA Tunas Luhur Paiton Probolinggo? Seberapa besar pengaruh Pengembangan Kurikulum PAI terhadappeningkatan prestasi belajar siswa SMA Tunas luhur Paiton Probolinggo?

\section{B. Pembahasan}

\section{Pengertian Pengembangan Kurikulum.}

Menurut Audrey Nichols dan S. Howard Nichools sebagaimana yang dikutip oleh Oemar Hamalik, bahwa pengembangan kurikulum (curriculum development) adalah sebagai berikut:

"the planning of learning opportunities intended to bring about certain desered in pupils, and assessment of the extent to which these changes have taken place". 5

Rumusan ini menunjukkan bahwa pengembangan kurikulum adalah perencanaan kesempatan-kesempatan belajar yang dimaksudkan untuk membawa siswa ke arah perubahan-perubahan yang diinginkan dan menilai hingga mana perubahan-perubahan itu telah terjadi pada diri siswa. Sedangkan yang dimaksud kesempatan belajar (learning opportunity) adalah hubungan yang telah direncanakan dan terkontrol antara peserta didik, guru, bahan peralatan dan lingkungan di mana belajar yang diinginkan diharapkan terjadi. Ini terjadi bahwa semua kesempatan belajar direncanakan oleh guru bagi peserta didik sesungguhnya adalah "kurikulum itu sendiri".

Dalam pengertian di atas sesungguhnya pengembangan kurikulum adalah proses siklus yang tidak pernah berakhir. Proses kurikulum tersebut dapat ditampilkan dalam diagram sebagai berikut: proses tersebut terdiri dari empat unsur yakni:

a. Tujuan:

Mempelajari dan menggambarkan semua sumber pengetahuan dan pertimbangan tentang tujuan-tujuan pengajaran, baik yang berkenaan dengan mata pelajaran (subject course) maupun kurikulum secara menyeluruh.

\section{b. Metode dan material:}

\footnotetext{
${ }^{5}$ Oemar Hamalik, Manajemen Pengembangan Kurikulum (Bandung: PT. Remaja Rosdakarya, 2008), 97.
} 
Mengembangkan dan mencoba menggunakan metode-metode dan material sekolah untuk mencapai tujuan-tujuan tadi yang serasi menurut pertimbangan guru.

\section{c. Penilaian (assessment):}

Menilai keberhasilan pekerjaan yang telah dikembangkan itu dalam hubungan dengan tujuan dan bila mengembangkan tujuantujuan baru.

\section{d. Balikan (feedback):}

Umpan balik dari semua pengalaman yang telah diperoleh yang pada gilirannya menjadi titik tolak bagi studi selanjutnya. ${ }^{6}$

Menurut UU No. 20 tahun 2003, kurikulum dianggap sebagai seperangkat rencana dan pengaturan mengenai tujuan, isi dan bahan pelajaran serta cara yang digunakan sebagai pedoman penyelenggaraan kegiatan pembelajaran untuk mencapai tujuan pendidikan tertentu. ${ }^{7}$

Menurut David Pratt, sebagaimana yang dikutip oleh Wina Sanjaya, bahwa istilah desain lebih mengena dibandingkan dengan pengembangan yang mengandung konotasi yang bersifat gradual. Disain adalah proses yang disengaja tentang suatu pemikiran, perencanaan dan penyeleksian bagian-bagian, teknik dan prosedur yang mengatur suatu tujuan atau usaha. Atas dasar itu, maka pengembangan kurikulum (curriculum development atau curriculum planning) adalah proses atau kegiatan yang disengaja dan dipikirkan untuk menghasilkan sebuah kurikulum sebagai pedoman dalam proses dan penyelenggaraan pembelajaran oleh guru di sekolah. ${ }^{8}$

Ada beberapa landasan utama dalam pengembangan suatu kurikulum, yaitu landasan filosofis, landasan psikologis, landasan sosial budaya, serta perkembangan ilmu dan teknologi.

\section{PengertianPendidikan Agama Islam}

Pendidikan Agama Islam (PAI) merupakan usaha sadar dan terencana untuk menyiapkan siswa dalam meyakini, memahami, menghayati dan mengamalkan ajaran Islam melalui kegiatan bimbingan, pengajaran dan atau latihan. Pendidikan Agama Islam (PAI) yang dipelajari oleh peserta didik dimaksudkan untuk membentuk peserta didik manusia yang beriman dan bertakwa kepada Tuhan Yang Maha Esa serta berakhlak mulia.

\footnotetext{
${ }^{6}$ Ibid., 96-97.

${ }^{7}$ Undang-Undang Sistem Pendidikan Nasional (Yogyakarta: Pustaka Pelajar, 2009), 6.

${ }^{8}$ Wina Sanjaya, Kajian Kurikulum dan Pembelajaran (Bandung: Sekolah Pascasarjana Universitas Pendidikan Indonesia, 2007), 48-49.
} 
Dasar spiritual pendidikan agama Islam yang paling utama ada dua, yaitu: al-Qur`an dan al-Sunnah.

\section{a. Al-Qur`an}

Secara lengkap al-Qur`an didefinisikan sebagai firman Allah yang diturunkan kepada hati Rasulullah, Muhammad Ibn Abdillah, melalui ruh alAmin dengan lafal-lafalnya yang berbahasa arab dan maknanya yang benar, agar menjadi hujjah bagi Rasul bahwa ia adalah Rasulullah, dan sebagai undang-undang bagi manusia dan memberi petunjuk kepada mereka, serta menjadi sarana pendekatan dan ibadah kepada Allah dengan membacanya. Ia terhimpun dalam sebuah mushaf, diawali dengan surat al-fatihah dan diakhiri dengan surat al-Nas, disampaikan kepada kita secara mutawatir baik secara lisan maupun tulisan dari generasi ke generasi, dan ia terpelihara dari berbagai perubahan atau pergantian. ${ }^{9}$

Islam adalah agama yang membawa misi umatnya menyelenggarakan pendidikan dan pengajaran. Al-Quran merupakan landasan paling dasar yang dijadikan acuan dasar hukum tentang Pendidikan Agama Islam. Firman Allah tentang pendidikan agama Islam dalam al-Quran Surat al-Alaq ayat 1 sampai ayat 5 , yang berbunyi sebagai berikut:

"Bacalah dengan (menyebut) nama Tuhanmu yang Menciptakan, Dia telah menciptakan manusia dari segumpal darah. Bacalah, dan Tuhanmulah yang Maha pemurah, Yang mengajar (manusia) dengan perantaran kalam, Dia mengajar kepada manusia apa yang tidak diketahuinya”.

\section{b. Al-Sunnah}

Al-Sunnah didefinisikan sebagai sesuatu yang didapatkan dari Nabi Muhammad SAW yang terdiri dari ucapan, perbuatan, persetujuan, sifat fisik atau budi, atau biografi, baik pada masa sebelum kenabian ataupun sesudahnya. ${ }^{10}$

Suatu hal yang sudah kita ketahui bersama bahwa Rasulullah Muhammad SAW diutus ke bumi ini, salah satu tugas utamanya adalah untuk memperbaiki moral atau akhlak umat manusia, sebagaimana sabdanya:

$$
\text { إنما بعثت لأتمم مكارم الأخحلاق }
$$

"Sesungguhnya aku diutus tiada lain adalah untuk menyempurnakan akhlak yang mulia".'

\footnotetext{
${ }^{9}$ Manna' Kholil al-Qattan, Mabahist fi Ulum al-Qur'an (Beirut: Dar al-Fikr, 2001), 23.

${ }^{10}$ Ajjaj Khatib, Ushul al hadis; 'ilmuhu wa musthalahuhu (Beirut: Dar al-Fikr, 2000),

${ }^{11}$ Ibid. 13.
} 


\section{Tujuan Pendidikan Agama Islam}

Pendidikan Agama Islam merupakan pendidikan yang berkesadaran dan bertujuan. Allah telah menyusun landasan pendidikan yang jelas bagi seluruh umat manusia melalui syariat Islam, termasuk tentang tujuan pendidikan agama Islam. Sebagai hamba Allah yang berserah diri kepada khaliknya, ia adalah hamba-Nya yang berilmu pengetahuan dan beriman secara bulat, sesuai kehendak pencipta-Nya untuk merealisasikan cita-cita yang terkandung dalam firman Allah SWT, QS. Al-An'am: 162:

Katakanlah: "Sesungguhnya sembahyangku, ibadatku, hidupku dan matiku hanyalah untuk Allah, Tuhan semesta alam".

\section{Kurikulum Pendidikan Agama Islam}

Secara rasional filosofis, pendidikan Islam bertugas untuk membentuk alinsan al-kamil atau manusia paripurna. Oleh karena itu, perlu diarahkan pada dua dimensi, yaitu: dimensi dialektikal horizontal, dan dimensi ketundukan vertikal. Adapun prinsip pengembangan kurikulum antara lain:

\section{a) Prinsip Kesinambungan (kontinuitas)}

Ajaran Islam, sangat memperhatikan prinsip kontinuitas, karena dengan berpegang pada prinsip ini, keputusan yang diambil oleh seseorang menjadi valid dan stabil (Q.S. 46: 13-14).

"Sesungguhnya orang-orang yang mengatakan: "Tuhan Kami ialah Allah, kemudian mereka tetap istiqamah. Maka tidak ada kekhawatiran terhadap mereka dan mereka tiada (pula) berduka cita. Mereka Itulah penghuni-penghuni surga, mereka kekal di dalamnya; sebagai Balasan atas apa yang telah mereka kerjakan”.

\section{b) Prinsip Menyeluruh (komprehensif)}

Prinsip yang melihat semua aspek, meliputi kepribadian, ketajaman hafalan, pemahaman ketulusan, kerajinan, sikap kerjasama, tanggung jawab (Q.S. 99: 7-8).

"Barangsiapa yang mengerjakan kebaikan seberat dzarrahpun, niscaya Dia akan melihat (balasan)nya. Dan Barangsiapa yang mengerjakan kejahatan sebesar dzarrahpun, niscaya Dia akan melihat (balasan)nya pula".

\section{c) Prinsip Objektivitas}

Dalam mengevaluasi berdasarkan kenyataan yang sebenarnya, tidak boleh dipengaharui oleh hal-hal yang bersifat emosional dan irasional. Allah SWT memerintahkan agar seseorang berlaku adil dalam mengevaluasi. Jangan sampai karena kebencian menjadikan evaluasi tidak obyektif. Nabi SAW pernah bersabda: 


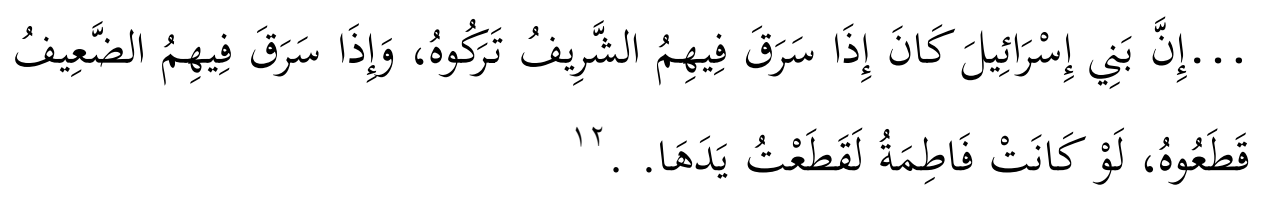

"Sesungguhnya dalam tradisi bani Israil ada suatu kebiasaan apabila seorang yang memiliki kedudukan (bangsawan) mencuri, maka mereka tidak menghukumnya, dan apabila yang lemah mencuri, maka mereka memotong tangannya. Andaikan Fatimah mencuri, maka akan aku potong tangannya".

\section{Faktor-faktor yang Mempengaruhi Keberhasilan Pendidikan Agama Islam.}

Faktor-faktor yang mempengaruhi keberhasilan Pendidikan Agama Islam antara lain:

\section{a) Pendidik}

Pendidik yang profesional dan kompeten akan mampu memainkan peran dan fungsinya dalam menjalankan tugas keguruannya secara proporsional dan mampu menjadi motivator serta fasilitator dalam proses belajar mengajar di sekolah.

\section{b) Peserta didik}

Peserta didik yang memiliki potensi,bersih hatinya dari kotoran dan penyakit jiwa, serta peserta didik yang menghiasi dirinya dengan akhlak yang mulia seperti bersikap benar, taqwa, ikhlas, zuhud, tawadhu' dan ridha. Peserta didik yang selalu menghormati gurunya dan selalu berusaha untuk senantiasa memperoleh kerelaan dari guru akan mampu mengembangkan diri menuju pribadi yang shalih.

\section{c) Kurikulum}

Kurikulum berbasis kompetensi yang selaras dengan fitrah insani, yaitu konsep kurikulum yang menekankan pada pengembangan kemampuan psikis, sosial, budaya, fisik, dan intelektual untuk melakukan kompetensi atau tugas-tugas dengan standar performansi tertentu, sehingga hasilnya dapat dirasakan oleh peserta didik, berupa penguasaan tehadap seperangkat kompetensi tertentu.

\section{d) Metode}

Metode pendidikan yang berdaya guna dan berhasil guna dan menimbulkan kesadaran anak didik untuk mengamalkan ketentuan ajaran agama Islam melalui teknik motivasi yang menimbulkan gairah belajar

12. Imam Bukhari, Shahih al-Bukhari (Maktabah Shamelah: Dar al-Thuq al-Najah, 1422 
anak didik secara mantap. Di samping berdaya guna untuk mengantarkan tercapainya tujuan pendidikan yang dicita-citakan.

\section{e) Sarana dan Prasarana}

Sarana dan prasarana yang bisa memotivasi belajar siswa terhadap ajaran agama Islam yang tidak terbatas hanya pada hal-hal yang berkaitan dengan barang atau peralatan, tetapi juga prosedur, teknik, dan strategi yang dikembangkan oleh pihak sekolah atau dari pihak pemerintah.

\section{Prestasi Belajar}

Dalam Kamus Kata Serapan, pengertian Prestasi adalah hasil tertinggi atau terbaik yang diperoleh dalam suatu kerja. ${ }^{13}$ Sedangkan pengertian belajar adalah proses yang di lakukan oleh individu untuk memperoleh perubahan perilaku baru secara keseluruhan, sebagai hasil dari pengalaman individu itu sendiri dalam berinteraksi dengan lingkunganya. ${ }^{14}$

Agar prestasi anak tercapai secara optimal. Menurut Bloom, ada tiga tujuan yakni ranah penalaran (Cognitive Domain) ranah nilai dan sikap (Affective Domain) dan ranah psikomotorik (Psychomotor Domain). ${ }^{15}$

\section{Metode Penelitian}

penelitian ini adalah penelitian lapangan dengan metode penelitian kuantitatif. Waktu di laksanakanya penelitian tentang pengaruh pengembangan kurikulum pendidikan agama Islam (PAI) terhadappeningkatan prestasi belajar siswa mata pelajaran PAIPengumpulan data menggunakan instrumen penelitian, analisis data bersifat kuantitatif dengan tujuan untuk menguji hipotesis yang telah ditetapkan.

Populasi dalam penelitian ini adalah semua siswa SMA Tunas Luhur Paiton Probolinggo tahun ajaran 2013-2014. Sedangkan Sampel merupakan bagian yang berfungsi mewakili populasi. ${ }^{16}$ Teknik pengambilan sampel dengan menggunakan random sampling.

Berdasarkan jumlah populasi yang ada, maka peneliti mengambil sampel sejumlah 20 siswa siswa SMA Tunas Luhur Paiton Probolinggo tahun ajaran 2013-2014 dengan alasan berdasarkan Suharsimi Arikunto jika subyeknya besar dapat diambil antara 10\%-15\% atau $20 \%-25 \%$.

\footnotetext{
${ }^{13}$ Surawan Martinus, Kamus Kata Serapan (Jakarta: PT Gramedia, 2008), 479

${ }^{14}$ Pupuh Faturrohman, dkk., Psikologi Pendidikan (Bandung: CV Pustaka Setia, 2010), 61.

${ }^{15}$ M. Ngalim Purwanto, Ilmu Pendidikan Teoritis dan Praktis (Bandung: PT Remaja Rosdakarya, 20017), 79.

${ }^{16}$ Ibid. 221.
} 


\section{Teknik Analisis Data}

Dalam melakukan analisis data, ada tiga tahap yang peneliti laksanakan yaitu:

\section{a) Analisis Pendahuluan}

Analisis pendahuluan dilakukan untuk mengetahui pengaruh Pengembangan Kurikulum mata pelajaran Pendidikan Agama Islam (PAI) di SMA Tunas Luhur Paiton Probolinggo periode 2013-2014. Data dianalisa dalam bentuk angka, yakni dalam bentuk kuantitatif. Langkah yang diambil dalam merubah data kualitatif menjadi kuantitatif adalah dengan memberi nilai pada setiap item jawaban pada pertanyaan angket untuk responden dan nilai prestasi belajar yang diperoleh siswa melalui hasil ulangan dan praktik.

Dalam analisis ini disajikan data hasil angket pengaruh pengembangan kurikulum Pendidikan Agama Islam (PAI) dan data peningkatan prestasi belajar siswa mata pelajaran PAI dari rekapitulasi nilai ulangan siswa.

\section{b) Analisis Uji Hipotesis}

Dalam analisis ini penulis menggunakan adalah analisis regresi satu prediktor dengan skor deviasi. Analisis ini digunakan untuk menguji kebenaran hipotesis yang diajukan. Dalam analisis uji hipotesis, peneliti menggunakan langkah-langkah sebagai berikut:

\section{1) Analisis Regresi Linear Satu Prediktor}

Analisis ini digunakan untuk mengetahui besarnya pengaruh antara variabel bebas dan variabel terikat. Untuk mengetahui pengaruh pengembangan kurikulum pendidikan agama Islam (X) dengan prestasi belajar (Y), maka peneliti menggunakan rumus persamaan regresi.

$$
Y=a+b X
$$

Keterangan:

Y: Kriterium/Variabel terikat

$\mathrm{X}$ : Prediktor/Variabel bebas

Nilai a dan b sendiri didapat dari persamaan hitung:

$b=\frac{n \sum x_{i} y_{i}-\sum x_{i} \sum y_{i}}{n \sum x_{i}^{2}-\left(\sum x_{i}\right)^{2}}$

$a=\bar{y}-b \bar{x}$

\section{2) Analisis Variasi Garis Regresi}


Untuk uji variasi garis regresi digunakan analisis nilai $F$ (uji- $F$ ) dengan rumus:

$$
F=\frac{M S R}{M S E}=\frac{S S R \div 1}{S S E \div(n-2)}
$$

Keterangan:

MSR: Mean of Squares garis regresi

MSE: Mean of Squares residu

SSR: Sum of Squares regresi

SSE: Sum of Squares residu

Harga $\mathrm{F}$ diperoleh $\left(\mathrm{F}_{\text {hitung }}\right)$ kemudian dikonsultasikan dengan harga $\mathrm{F}_{\text {tabel }}$ pada saat signifikansi $1 \%$ dan $5 \% \mathrm{db}=\mathrm{N}-2$ hipotesis diterima jika $F_{\text {hitung }}$ hitung $>F_{\text {tabel. }}$

\section{c) Analisis lanjut}

Analisis lanjut merupakan pengolahan lebih lanjut dari hasil analisis uji hipotesis. Analisis ini peneliti membuat interpretasi dari hasil tes telah diproses antara variabel $\mathrm{x}$ dan variabel $\mathrm{y}$.

Setelah diperoleh persamaan regresi antara variabel $\mathrm{x}$ dan variabel $\mathrm{y}$, maka langkah selanjutnya adalah menghubungkan antara nilai frekuensi dengan nilai $\mathrm{F}$ pada tabel, baik taraf signifikansi $5 \%$.

Apabila nilai yang dihasilkan dari Fhitung $\geq$ Ftabel maka hasil yang diperoleh adalah signifikansi yang berarti hipotesis diterima. Namun bila nilai yang dihasilkan dari Freg < Ftabel maka hasil yang diperoleh adalah non signifikansi yang berarti hipotesis yang diajukan ditolak.

\section{Pembahasan}

\section{Pengembangan Kurikulum Pendidikan Agama Islam}

Data pengembangan kurikulum pendidikan agama Islam SMA Tunas Luhur diperoleh dari nilai penyelenggaraan pendalaman materi keagamaan yang dikelola dalam program TPQ. Materi keagamaan tersebut secara lebih spesifik diberikan dalam lingkup pendalaman tentang fashohah dan tartil, ghorib, tajwid, hafalan surat pendek, do'a harian, praktek sholat, praktek wudlu', dan hadits. Berikut pada Tabel 1.1 disajikan data nilai pengembangan kurikulum pendidikan agama Islam di SMA Tunas Luhur dari 20 orang siswa yang dijadikan sampel. 
Tabel: 1.1

Nilai Pengembangan Kurikulum Pendidikan Agama Islam

\begin{tabular}{|c|c|c|c|c|c|c|c|c|c|}
\hline \multirow{3}{*}{ No. } & \multicolumn{8}{|c|}{$\begin{array}{c}\text { Variabel Pengembangan } \\
\text { Kurikulum PAI }\end{array}$} & \multirow{3}{*}{$\begin{array}{r}\text { Jumlh } \\
\text { Nilai }\end{array}$} \\
\hline & \multicolumn{3}{|c|}{$\begin{array}{c}\text { Keterampilan } \\
\text { Membaca } \\
\text { Al-Qu'an }\end{array}$} & \multicolumn{2}{|c|}{$\begin{array}{c}\text { Hafalan } \\
\text { Surat } \\
\text { dan } \\
\text { Hadits }\end{array}$} & \multicolumn{3}{|c|}{ Prktk Ibdah } & \\
\hline & A & $\mathrm{B}$ & $\mathrm{C}$ & $\mathrm{D}$ & $\mathrm{E}$ & $\mathrm{F}$ & $\mathrm{G}$ & $\mathrm{H}$ & \\
\hline 1 & 8 & 9 & & 10 & 10 & 10 & 10 & 10 & 73,0 \\
\hline 2 & 7,5 & 9 & & 9 & y & 10 & 8 & 9 & 67,5 \\
\hline 3 & 8 & 9 & & 10 & 10 & 10 & 9 & 10 & 74,0 \\
\hline 4 & 7,5 & 8 & & 8 & 9 & 10 & 9 & 10 & 69,5 \\
\hline 5 & 8,5 & 10 & 5 & 10 & 9 & 10 & 9 & 9 & 74,5 \\
\hline 6 & 9 & 6 & & 8 & & 7 & 8 & 8 & 58,0 \\
\hline 7 & 8,5 & 10 & 10 & 10 & 10 & 10 & 10 & 10 & 78,5 \\
\hline 8 & 7,5 & 10 & & 10 & & 10 & 9 & 8 & 72,5 \\
\hline 9 & 8,5 & 9 & & 6 & 10 & 10 & 7 & 8 & 66,5 \\
\hline 10 & 8,5 & 10 & & 8 & 9 & 10 & 8 & 9 & 68,5 \\
\hline 11 & 7,5 & 7 & & 8 & & 9 & 10 & 10 & 61,5 \\
\hline 12 & 8 & 10 & & 8 & $P$ & 9 & 9 & 10 & 70,0 \\
\hline 13 & 8,5 & 9 & 10 & 10 & 10 & 10 & 10 & 9 & 76,5 \\
\hline 14 & 8 & 7 & & 8 & 9 & 9 & 7 & 9 & 63,0 \\
\hline 15 & 8,5 & 9 & & 8 & 9 & 10 & 9 & 9 & 70,5 \\
\hline 16 & 7,5 & 10 & 8 & 10 & 10 & 10 & 10 & 10 & 75,5 \\
\hline 17 & 8,5 & 7 & 10 & 10 & 9 & 10 & 7 & 10 & 71,5 \\
\hline 18 & 7,5 & 10 & 8 & 10 & 8 & 10 & 8 & 9 & 70,5 \\
\hline 19 & 7,5 & 9 & 7 & 10 & 7 & 10 & 10 & 9 & 69,5 \\
\hline 20 & 8,5 & 10 & 8 & 10 & 9 & 10 & 10 & 10 & 75,5 \\
\hline
\end{tabular}

Keterangan: $\mathrm{A}=$ Fashohah dan tartil $; \mathrm{B}=$ Ghorib $; \mathrm{C}=$ Tajwid $; \mathrm{D}=$ Surat pendek; $\mathrm{E}=$ Hafalan hadits; $\mathrm{F}=$ Doa harian; $\mathrm{G}=$ Praktek sholat; dan $\mathrm{H}=$ Praktek wudlu'

Data diatas kemudian dikelompokkan ke dalam kelas-kelas interval yang banyaknya ditentukan berdasarkan rumus:

Jumlah kelas interval $(k)=1+3,3 \log n$

Panjang kelas interval $(c)=\frac{J}{k}$, dengan Jangkauan $(J)=x_{\text {max }}-x_{\text {min }}$ 
Dengan demikian, diperoleh jumlah kelas interval data:

$$
\begin{aligned}
& k=1+(3,3)(\log 20) \\
& =1+(3,3)(1,301) \\
& =1+4,293 \\
& =5,293 \approx 5 \text { (dibulatkan })
\end{aligned}
$$

Dengan $J=78,5-58=20,5$ dan $k=5$, dapat dihitung panjang kelas $(c)$ untuk masing-masing kelas interval, yaitu:

$$
\begin{aligned}
& c=20,5 \div 5 \\
& =4,1 \approx 5 \text { (dibulatkan) }
\end{aligned}
$$

Selanjutnya, berdasarkan perhitungan diatas tabel, distribusi frekuensi berkelompok dapat disusun sebagaimana pada Tabel 4.5 untuk kemudian mencari nilai standar deviasi atau simpangan bakunya $\left(\sqrt{S^{2}}\right)$.

Tabel: 1.2

Tabel Distribusi Frekuensi Data Berkelompok tentang PengembanganKurikulumPendidikan Agama Islam

\begin{tabular}{|c|c|c|c|r|r|r|}
\hline $\begin{array}{c}\text { Kelas } \\
\text { Interval }\end{array}$ & $\begin{array}{c}\text { Frek. } \\
\left(f_{i}\right)\end{array}$ & $\begin{array}{c}\text { Nilai } \\
\operatorname{Tgh}\left(x_{i}\right)\end{array}$ & $f_{i} x_{i}$ & $\begin{array}{l}x_{i} \\
-\bar{x}\end{array}$ & $\begin{array}{c}\left(x_{i}\right. \\
-\bar{x})^{2}\end{array}$ & $\begin{array}{c}f_{i}\left(x_{i}\right. \\
-\bar{x})^{2}\end{array}$ \\
\hline $58-62$ & 2 & 54 & 108 & $\begin{array}{r}- \\
11,5\end{array}$ & 132,25 & 264,50 \\
\hline $63-67$ & 2 & 59 & 118 & $-6,5$ & 42,25 & 84,50 \\
\hline $68-72$ & 7 & 64 & 448 & $-1,5$ & 2,25 & 15,75 \\
\hline $73-77$ & 6 & 69 & 414 & 3,5 & 12,25 & 73,50 \\
\hline $78-82$ & 3 & 74 & 222 & 8,5 & 72,25 & 216,75 \\
\hline Jumlah & 20 & & 1310 & & 261,25 & 655 \\
\hline
\end{tabular}

Simpangan baku merupakan akar dari ragam $\left(S^{2}\right)$ yang dapat dirumuskan:

$$
\text { Simpangan baku }\left(\sqrt{S^{2}}\right)=\sqrt{\frac{\sum_{i=0}^{n} f_{i}\left(x_{i}-\bar{x}\right)^{2}}{\sum_{i=0}^{n} f_{i}}}
$$

Dengan demikian, diperoleh perhitungan untuk simpangan baku data hasil penelitian sebagai berikut.

$$
\sqrt{S^{2}}=\sqrt{\frac{655}{20}}=\sqrt{32,75}=5,723
$$

Simpangan baku ini digunakan untuk menghitung batas-batas nilai untuk konversi nilai dengan standar-lima, seperti ditunjukkan pada: 
Tabel: 1.3

Rumus dan Hasil Perhitungan Konversi Nilai DataPengembangan Kurikulum dalam Skala-Lima

\begin{tabular}{|l|c|c|}
\hline \multicolumn{1}{|c|}{ Kategori } & $\begin{array}{c}\text { Rumus Konversi } \\
\text { Skala-Lima }\end{array}$ & Hasil Perhitungan \\
\hline Istimewa $(A)$ & $A>\bar{x}+1,5 \sqrt{S^{2}}$ & $\begin{array}{c}A>66+(1,5)(5,723) \\
\Leftrightarrow A>74,084 \approx 74\end{array}$ \\
\hline Baik $(B)$ & $\bar{x}+0,5 \sqrt{S^{2}}<B$ & $68<B \leq 74$ \\
& $\leq \bar{x}+1,5 \sqrt{S^{2}}$ & \\
\hline Cukup $(C)$ & $\bar{x}-0,5 \sqrt{S^{2}}<C$ & $63<C \leq 68$ \\
& $\leq \bar{x}+0,5 \sqrt{S^{2}}$ & \\
\hline Kurang $(D)$ & $\bar{x}-1,5 \sqrt{S^{2}}<D$ & $57<D \leq 63$ \\
& $\leq \bar{x}-0,5 \sqrt{S^{2}}$ & \\
\hline Buruk $(E)$ & $E \leq \bar{x}-1,5 \sqrt{S^{2}}$ & $E \leq 57$ \\
&
\end{tabular}

Dari data diatas, dapat diketahui bahwa nilai rata-rata pengembangan kurikulum pendidikan agama Islam terhadap siswa SMA Tunas Luhur yang sebesar 66 berada dalam kategori "cukup".

\section{Analisis Data Hasil Penelitian}

Analisisini digunakan untukmembuktikan diterima atau ditolaknya hipotesis yang diajukan oleh peneliti.Adapun hipotesis yang diajukan oleh peneliti adalah "terdapat pengaruh yang signifikan dalam pengembangan kurikulum pendidikan agama Islam terhadap prestasi belajar mata pelajaran PAI siswa SMA Tunas Luhur Paiton Probolinggo". Model regresi linear sederhana (dua variabel) digunakan untuk membuktikan hipotesis tersebut. Untuk mempermudah langkah-langkah analisis regresi, maka data-data hasil angket mengenai pengembangan kurikulum PAI dan prestasi belajar mata pelajaran PAI siswa SMA Tunas Luhur dirangkum sebagaimana pada Tabel 4.10. 
Dalam penelitian ini, model regresi dibuat untuk mengetahui tingkat pengaruh pengembangan kurikulum pendidikan agama Islam (sebagai variabel bebas, dilambangkan $x$ ) terhadap prestasi belajar mata pelajaran pendidikan agama Islam (variabel terikat, dilambangkan $y$ ) siswa SMA Tunas Luhur. Secara umum, persamaan regresi sederhana dirumuskan:

$$
Y=a+b X, \text { dengan: }
$$

$b=\frac{n \sum x_{i} y_{i}-\sum x_{i} \sum y_{i}}{n \sum x_{i}{ }^{2}-\left(\sum x_{i}\right)^{2}}$

$a=\bar{y}-b \bar{x}$

Dari data penelitian, diperoleh perhitungan:

$b=\frac{(100)(695269)-(8543)(8124)}{(100)(733241)-(8543)^{2}}$

$b=\frac{69526900-69403332}{73324100-72982849}$

$b=\frac{123568}{341251}$

$b=0,3621$

dan

$a=81,24-(0,3621)(85,43)$

$a=50,306$

Sehingga persamaan linearnya menjadi:

$$
Y=50,306+0,3621 X
$$

Persamaan diatas menunjukkan bahwa setiap peningkatan satu satuan pada variabel $X$ (pengembangan kurikulum pendidikan agama Islam) akan meningkatkan prestasi belajar mata pelajaran pendidikan agama Islam siswa sebesar 0,3621 .

\section{E. Penutup}

\section{Kesimpulan}

Berdasarkan hasil analisis korelasi, pengembangan kurikulum pendidikan agama Islam dan prestasi belajar mata pelajaran PAI siswa SMA Tunas Luhur Paiton Probolinggo mempunyai hubungan yang kuat atau signifikan dengan ditunjukkan oleh nilai $r$ hasil perhitungan $(0,681)$ yang lebih besar dari $r_{\text {tabel }}(0,444)$ pada taraf signifikansi 5\%. Selain itu, dari hasil analisis regresi diperoleh kesimpulan bahwa pengembangan kurikulum memberikan pengaruh yang positif terhadap prestasi belajar PAI, ditandai dengan nilai slope (kemiringan) garis regresi positif sebesar 0,690. Persamaan regresi yang diperoleh $(Y=35,558+0,690 X)$ juga dapat menjelaskan keragaman nilai prestasi belajar siswa secara signifikan didasarkan pada hasil analisis lanjut dengan uji-nilai- $F(15,548)$ yang lebih besar dari $F_{\text {tabel }}(4,41)$ 
pada taraf signifikansi 5\% dan dengan uji nilai coefficient of determination $\left(r^{2}\right)$ sebesar 0,463. Secara keseluruhan, dengan demikian, hipotesis yang diajukan diterima, yaitu bahwa terdapat pengaruh (positif) yang signifikan dari pengembangan kurikulum pendidikan agama Islam terhadap prestasi belajar mata pelajaran PAI siswa SMA Tunas Luhur Paiton Probolinggo.

\section{Saran}

Dari hasil penelitian mengenai pengembangan kurikulum pendidikan agama Islam, Sekolah hendaknya terus memperkaya jenis-jenis kegiatan yang mampu meningkatkan kesadaran keberagamaan siswa, tidak saja yang terkait dengan pendalaman penguasaan materi, namun dapat juga dengan mengembangkan kegiatan ekstrakurikuler seni Islami semisal kaligrafi, hadrah, dan semacamnya. Bagi para guru, selain terus berupaya mengintegrasikan ilmu pengetahuan umum dengan ilmu dan nilai-nilai agama

Para siswa juga aktif berpartisipasi dalam program-program yang sekolah selenggarakan untuk meningkatkan semangat dan prestasi dalam bidang keilmuan dan keislaman. 


\section{Daftar pustaka}

Abrasyi [al], Athiyah. Dasar-dasar Pokok Pendidikan Islam, terj. H. Bustami A. Ghani dan Johar Bahri L.I.S. Jakarta: Bulan Bintang. 1986.

Faturrohman, Pupuh. dkk., Psikologi Pendidikan. Bandung: CV Pustaka Setia, 2010.

Hamalik, Oemar. Manajemen Pengembangan Kurikulum. Bandung: PT. Remaja Rosdakarya, 2008.

Idi, Abdullah. Pengembangan Kurikulum Teori dan Praktik. Yogyakarta: ArRuzz Media. 2009.

Khatib, Ajjaj. Ushul al hadis; 'ilmuhu wa musthalahuhu. Beirut: Dar al-Fikr, 2000.

Majid, Abdul, dkk.Pendidikan Agama Islam Berbasis Kompetensi, konsep dan Implementasi Kurikulum 2004. Bandung: Remaja Rosdakarya. 2004.

Martinus, Surawan. Kamus Kata Serapan. Jakarta: PT Gramedia. 2008.

Ma'arif, Syamsul. Pendidikan pluralisme di Indonesia. Yogyakarta: Logung Pustaka. 2005.

Mudjiono, Dimyati. Belajar dan Pembelajaran. Jakarta: PT. Rineka Cipta. 2009."

Nurgiyantoro, Dasar-Dasar Pengembangan Kurikulum Sekolah; Sebuah Pengantar Teoritis dan Pelaksanaan. Yogyakarta: BPFE, 1988.

Nasution, s. Asas-asas Kurikulum. Bandung: Jemmars, 1980”

Rahmat. RaharjO. Inovasi Kurikulum Pendidikan Agama Islam pengembangan kurikulum dan pembelajaran. Depok Sleman: Magnum Pers. 2010.

Purwanto, M. Ngalim. Ilmu Pendidikan Teoritis dan Praktis. Bandung: PT Remaja Rosdakarya. 20017.

Qattan [al], Manna' Kholil. Mabahist fi Ulum al-Qur'an. Beirut: Dar al-Fikr, 2001.

Rosyadi, Khoiron. Pendidikan Profetik. Yogyakarta: Pustaka Pelajar. 2004.” 
Sanjaya, Wina. Kajian Kurikulum dan Pembelajaran. Bandung: Sekolah Pascasarjana Universitas Pendidikan Indonesia. 2007.

Undang-Undang Sistem Pendidikan Nasional. Yogyakarta: Pustaka Pelajar. 2009 